\title{
GCU
}

Glasgow Caledonian

University

University for the Common Good

\section{Conceptualizing impact in academic development: finding a way through}

Jones, Anna; Lygo-Baker, Simon; Markless, Sharon; Rienties, Bart; Di Napoli, Roberto

Published in:

Higher Education Research and Development

DOI:

$10.1080 / 07294360.2016 .1176997$

Publication date:

2017

Document Version

Author accepted manuscript

Link to publication in ResearchOnline

Citation for published version (Harvard):

Jones, A, Lygo-Baker, S, Markless, S, Rienties, B \& Di Napoli, R 2017, 'Conceptualizing impact in academic development: finding a way through', Higher Education Research and Development, vol. 36, no. 1, pp. 116-128. https://doi.org/10.1080/07294360.2016.1176997

\section{General rights}

Copyright and moral rights for the publications made accessible in the public portal are retained by the authors and/or other copyright owners and it is a condition of accessing publications that users recognise and abide by the legal requirements associated with these rights.

Take down policy

If you believe that this document breaches copyright please view our takedown policy at https://edshare.gcu.ac.uk/id/eprint/5179 for details of how to contact us. 
Conceptualising impact in academic development: Finding a way through

Jones, $\mathrm{A}^{1}$., Lygo-Baker, $\mathrm{S}^{2}$., Markless, $\mathrm{S}^{3}$., Rienties, $\mathrm{B}^{4}$. \& Di Napoli, R55.

\footnotetext{
${ }^{1}$ Glasgow Caledonian University

${ }^{2}$ University of Surrey

${ }^{3}$ King's College London

${ }^{4}$ Open University

${ }^{5}$ Kingston University
} 


\begin{abstract}
This paper explores the notion of impact in the context of academic development programs and considers how it can be described and understood. We argue that impact has a range of meanings and academic development programs such as graduate certificates have a broad group of stakeholders and hence the impact is different for each group depending on how the program aims and objectives are defined and understood. In finding a way through the difficulties of evaluating impact in academic development we point to the importance of clearly conceptualizing the notion of impact, a careful identification of the assumptions underpinning any program and an understanding of who academic development will benefit and how. We suggest that impact in academic development cannot be understood without taking account of the range of possible impacts and the difficulty of attributing simple cause and effect to a complex environment.
\end{abstract}




\section{Introduction}

While academic development programs have become an almost ubiquitous feature of the Higher Education landscape in many countries, including the UK, Australasia and parts of Europe, examining the impact of these programs is a complex prospect. This paper argues that before considering the impact, it is necessary to define what it means. This is a conceptual paper that draws on our experiences evaluating a new academic development program at one university in England. The program was a restructured and re-thought Graduate Certificate in Academic Practice and this paper explores the possible ways of conceptualising impact in this context. Academic development can be understood in different ways interpreted differently internationally, nationally and between institutions. For this paper we define academic development as work focussed on the enhancement of individuals involved in teaching and their subsequent engagement with learning whether this be through notions of student development, curriculum design or work with peers. We argue that it is the multiple nature of impact that has led to difficulties in defining whether academic development programs such as these have been effective. Because there are a number of stakeholders with differing aspirations, there have been multiple expectations as to what an 'effective' program might achieve. Moreover, there are a number of ways in which this effectiveness can be judged. As a consequence the notion of impact in academic development is highly contextual.

We suggest that without a clearer understanding of the context, and the framework that has been applied to assess the effectiveness of academic development, the value of such programs is likely to remain in question. This paper explores the ways in which the impact of academic development can be conceptualized and the implications for practice. While there has been valuable work in this area (Chalmers \& Gardiner 2015; Gray \& Radloff 2008; Kreber \& Brook 2001; Stefani 2010), we consider this in the light of our experience in devising an evaluation of the impact of one academic development program. The 
focus of this paper is not on the findings of the evaluation but on our efforts to conceputualise impact in this context.

\section{Conceptualising impact}

Before examining how the notion of impact can be understood in academic development, we unpack it in relation to a wider higher education literature on the topic. Undertaking such a review immediately highlights the reasons why problems may arise when evaluating the impact of academic development in higher education. The notion of 'impact' is a notoriously contested one (Garbarino and Holland, 2009; Stes, Min-Leliveld, Gijbels \& Van Petegem 2010) but terms such as 'impact', 'excellence' and 'quality', underpin current discourses taking place in higher education today and so are worth careful unpacking. A cursory examination of a recent UK Government White Paper highlights the use of the term 'impact' (BIS, 2011:50) stating they "will monitor the impact of this new approach and its effect on supply and demand, and will take advice from HEFCE for implementation in 2013/14 and beyond." In central UK governmental policy, impact is a key priority. In Australia the current Minister for Education, commented 'I remain committed to ensuring Australia has the best higher education system in the world and believe we need a strong focus on the quality and impact of higher education learning and teaching," (Department of Education and Training 2014). A review of the literature for the OECD (Henard \& Leprince-Ringuet 2008) on quality teaching in higher education makes clear reference to 'impact and quality assurance of teaching' (p6).

Considered as a linear concept, impact implies a direct causal relationship between an action and the resultant outcome. This view is increasingly witnessed in current higher education discourse, where impact is conceived as something that is measureable and the result of carefully planned actions within established time frames (usually short-term), that seek to bring about definable improvement in a given set of activities. In universities, this has centred on teaching and research (Morley, 2003). Linearity between action and impact is suggested by an assumption that teaching interventions or research development will result in clear outcomes. Such a linear definition is, however, 
problematic for those in academic development, where outcomes are less directly attributable to a single act and change may take time to come to fruition, be subtle and possibly take multiple forms.

Some literature offers a more nuanced understanding of the notion of impact. For example, Smutylo (2001:2) suggests that "outcomes often occur a long way downstream and may not take the form anticipated". While recognizing a noncausal nature of impact, this also gives it a serendipitous character, suggesting it may be as much luck as good planning. In other words, it is argued that impact can be felt, over a longer time frame and within unforeseen consequences. Such a view gives a more multifaceted and, some argue, a more realistic view of its nature and scope within multi-layered or 'supercomplex' contexts (Barnett, 2000) like contemporary universities, where immediate relationships between cause and effect are not always possible, nor perhaps desirable. Such a definition also allows for more appreciation of the complexity of learning and teaching, two activities that do not necessarily have a discrete one-to-one relationship, as they may follow unexpected paths in their interactions within given environments and can be affected by extraneous factors.

Beyond higher education there is a well-published disagreement between those who see impact as "any difference discerned in the indicator of interest that can be attributed to the intervention" and those who believe that it is complex, often emergent, encompassing changes that may be primary or secondary, direct or indirect, intended or unintended (White, 2010:154). There is a danger that this suggests a rather unsophisticated picture based around two extreme positions. The reality may be a shifting pattern of convergence and divergence across different groups in relation to how impact is perceived. Impact is social and cultural and as such meanings and intentions are shaped and filtered by groups and individuals who then attribute new understandings to them, in relation to various expectations and value systems that are not necessarily in alignment with one another. If the meaning of impact is understood as social then the situation may be even more complicated, according to Breakwell (1986). She argues that a complex interplay is constantly occurring between the values an 
individual brings to a particular role and the values recognized as appropriate to be displayed through the discharge of that role. Whilst this suggests that there is a shared understanding around each role in terms of actions and intentions, groups are in fact made of individuals who may diverge and align with different parts of each group they encounter. It is not simply a question of 'us' and 'them' but of prevailing definitions against counter groups. So if, in the case of academic development, impact is connected to a particular role the meaning of that impact will vary. This is why it is important not only to quantify impact but also to qualify it in relation to each group, to make reference to individuals operating within a specific context, and to describe impact in a rich, qualitative manner.

\section{Impact and academic development}

Taking a position on impact in relation to academic development demands careful reflection on the nature of the enterprise and its purposes. There is an absence of a unified view of academic development, its goals and underpinning philosophy. As Land (2004) found, there are at least eleven orientations to which academic developers align themselves. Whilst a variety of approaches and beliefs may be a strength, it further complicates our ability to define impact in academic development and to outline the most effective approach to undertaking evaluation. In this research, the focal program was designed to develop those with responsibility to support student learning through understanding the complex interrelationship between learning and teaching.

In our attempts to identify the impact of this program it became apparent that there were significant challenges. An initial difficulty is the term 'development', which is loaded with implications of deficit and as Webb (1996) suggested many years ago, may be a cursed term for that reason. Manathunga (2006) takes up this critique of academic development, suggesting that the notion of development has undertones of colonialism and the debate about the nature and purpose of academic development and the assumptions upon which it is based continues (Loads \& Campbell 2015; Peseta 2014; Sutherland 2013). Even the name is fluid - academic development/educational development - suggesting shifting emphasis. While in certain contexts academic development is also taken 
to refer to both staff and student support, and to take a range of forms discipline specific or general, informal or formal, voluntary or mandated, large group or individual, credit bearing or not - in this particular case it is understood to be a formal education program for new academic staff centred around understanding learning and teaching.

Southwell \& Morgan (2010) in a review of the literature on the impact of various forms of academic development programs on student learning conclude that while it is difficult to draw a clear cause and effect relationship it is possible to have 'cautious optimism' particuluarly in the case of longer term programs. However, citing Bamber et al (2006) they comment that academic development programs are subject to a range of influences including the organizational culture, discipline specific considerations, the policy agenda and the diverse goals of academic developers. A recent study into the impact of the UK Professional Standard Framework for teaching in higher education (Turner et al 2013) considers levels of impact from those unaware of the framework through to publically available evidence of a change of practice as a result of the framework. While the authors do not problematize the concept of impact, they consider the range of ways in which it can be evidenced.

Identifying the impact of academic development is a reasonable ambitition. Each academic centre or unit must be funded by the university, staff attending the programs must invest a considerable amount of time and effort in the course and each program relies upon the skill and knowledge of those staff delivering it and on an assumption that academic staff should learn to teach in this particular context and format.

It was against this challenge that a team of academic developers began to consider how to report the impact of a new program delivered at one university. The program considered in this paper is a Graduate Certificate in Academic practice, which is a formal, credit-bearing university qualification for new academic staff run over an academic year. Although the particulars of the 
program may be contextual, we suggest that the debate about the impact of such programs is far reaching.

Given that the purposes of academic development are myriad and possibly conflicting, the first challenge was to articulate our definition of impact at the outset. In order to do this it was necessary to outline the purposes of this academic development program as understood by the team. We drew on Kreber (2011), who argues that despite seemingly conflicting agendas she believes it is possible to find an overarching purpose. She suggests using Aristotelian concepts, i.e. rather than providing techne or an understanding of principles and theories, the purpose of academic development is to provide phronesis, or practical wisdom, which encompasses a critical dialogue. This echoes the work of Palmer (1998) who argues for the development of connections between learners, teachers and knowledge. He argues this happens through dialogue and requires teachers to be aware of their own influences. Further, what is important is discussion of the provision of teaching rather than merely a series of tips on technique. Similarly, Kreber suggests that one of the central purposes of academic development is to provide an opportunity for academics to engage in dialogue within and across disciplines about "what it means to teach and learn in the context of our times" (53). Further, she emphasises the importance of criticality, in which academic development enables assumptions to surface and be explored. This resonates with Rowland's (2003) notion of critical interdisciplinarity in which academics are provided with opportunities to meet and challenge each other in cross-disciplinary spaces. Kreber suggests that rather than basing academic development programs on more and more 'techne' or technical knowledge, instead they should establish opportunities where participants are encouraged to make judgments about what the 'wise' thing to do is in each particular situation. Thus, if the focus of academic development in this program is interdisciplinarity and judgement based, then this needs to be reflected in any evaluation of impact.

Kreber's (2011) argument that academic development should focus on situational wisdom rather than large quantities of technical knowledge is 
supported by the literature on professionalism and professional learning. According to Coles, learning about a particular role should encourage the "professional capacity of judgment to deal with uncertainty, and that underpinning that judgement is the professional's 'practical wisdom'” (2013: 48). Again, a consideration of process comes to the fore as Coles' work suggests that to make a judgement about impact we need not only to consider outcomes but also to examine the process of reflecting upon and changing teaching. This is challenging because academic developers are often working with staff who are new to their role in the university. According to Eraut (2000) a significant challenge for people beginning a new role is coming to terms with implicit or tacit knowledge in an organisation. For each academic some of this may have been absorbed through disciplinary socialization but tacit institutional knowledge is different in each setting.

In evaluating the impact of academic development in this spirit the focus is not on identified outcomes at the conclusion of an intervention but rather on the process of change. A mixed method study of participants on this particular program found they did form interdisciplinary links and hence engaged in some form of critical inter-disciplinarity (Rienties and Kinchin 2014). Thus one of our aims was to consider impact in terms of process i.e. the opportunity for academics to come together and examine ideas about teaching and learning in critical and constructive ways. However, we considered that although the focus was on process while participants were engaged in the program, at a point in the future they may be able to see the value of this in the light of their own teaching experiences. While immediate outcomes were important, recognising outcomes after the program was completed are also important albeit more difficult to capture.

From a functionalist perspective undertaking such a review can be seen as relatively simplistic. The change, recognised through a process of socialization, where individuals acquire relevant competencies and values that become internalised by each academic, is viewed as relatively unproblematic (Atkinson \& Delamont, 1985). Those who follow this approach argue that whilst an individual 
may have some challenge in moving from one position to another, the relationship between professional socialization and practice is relatively continuous. As such, over time an individual will be able to make any change apparent and acquire the relevant level of competency and understand the relevant values, incorporating these into their own actions. Such a view would support a linear and outcome based model of impact. From this viewpoint, impact could be determined by evaluating against a set of outcomes.

Interactionists (Atkinson \& Delamont 1985), challenge these assumptions, suggesting a more dynamic view of socialisation. The period of 'professional' learning they depict is one of discontinuity, not a steady and uniform transition. Whereas a functionalist view implies that academics are able to develop similar perspectives and subscribe to common values, interactionists emphasize the possibility of conflict as values do not necessarily match or easily transform. Kramer (1974) suggests that this can present a 'reality shock' which can lead to feelings of confusion, loss, disorientation and doubt. For an academic, this may be made worse by the fact that the teaching element of their role is not always one they have been well prepared for. The sudden introduction of decontextualised new theories central to many academic development programs can be disconcerting, as Kramer suggests. From this viewpoint, impact should be evaluated by considering the role of academic development in socialization into an academic career over a period of time. While we suggest that this is important, it is more difficult if only immediate, short-term statements of impact are required.

Impact can therefore be understood from a range of perspectives, each requiring a different evaluative approach. Examination of impact then begs the question 'impact for whom'? Academic development can be seen as operating at a range of levels and hence in exploring impact we could have framed this simply against impact on the participants of our program as perhaps the most obvious stakeholders. This could be evidenced through changed teaching practices and the resultant changed learning opportunities for students. However, this immediately raises the challenge of establishing direct causal connections 
between teaching and learning, which is by no means clear. Even if we concentrate on impact upon an individual academic there are still a range of possible outcomes, such as basic teaching skill, an introduction to the profession, networking and understanding the institution's strategic priorities (Fanghanel 2012) which would be particular to each individual's set of needs. An alternative consideration could conceive of impact based on compliance with quality assurance requirements. The stakeholder focus would then apply to those with a remit to consider audit data such as quality standards, for example associate deans for learning and teaching or the equivalent. This may be easier to measure but may say less about learning and education. Another approach would be to consider impact from a strategic, institutional perspective, viewing the key stakeholders as the senior management team (Gosling 2001). Another possibility might be to see it as institutional, departmental and individual (Smith 2004) and consider the needs of stakeholders at each of these levels. In addition, an examination of the impact of academic development might also consider the needs of students.

\section{Evaluating Impact}

Given the complex debates about the nature of impact it is not surprising that evaluating it has generated controversy. As White (2010) points out, different definitions of impact lead to completely different models of impact evaluation and specifically to fundamental methodological differences. Researchers on opposite sides of the debate have conflicting views about what constitutes sufficient and appropriate evidence. For some, impact evaluation can only be researched by discerning causal chains linking program inputs and activities directly to intended or observed outputs (Ebert-May, Derting, Hodder, Momsen, Long \& Jardeleza 2011; Rienties, Brouwer \& Lygo-Baker 2013; Stes, Coertjens \& Van Petegem 2010). Others however, prefer open, flexible studies that make no attempt to attribute changes to particular interventions but use a more complex theory of change (White, 2010; Rogers, 2008).

When considering how to evaluate the impact of an academic development program in higher education we are pushed into the centre of this far-reaching 
debate. This requires us to go back to examining our own values and beliefs about the nature and purposes of such programs in order to adopt a defensible position on evaluating its impact and a means of evaluating that captures the original aims of the program. This immediately causes difficulty because it is evident that academic developers themselves exhibit different beliefs about the aims they, and the programs they conceive, are attempting to fulfil (Lygo-Baker, 2006). Thus evaluating the impact of a program is a daunting prospect and particularly problematic as frameworks that could help highlight causality are difficult to articulate for academic development (Stefani, 2011). Debowski (2011) argues that even if we accept that the aim of academic development is to educate, influence and enable change across a university it is not easy to establish the extent to which the aims are fulfilled because any causal relationships that would qualify these are very difficult to establish.

Despite the challenges, there has been work that has attempted to measure and benchmark the work of academic development. Rivers (2005) examined the impact of academic development units (ADU) on the basis of two propositions: first, that good teaching has positive effects on student outcomes and secondly that through ADU interventions teachers can improve their teaching. However, while there has been research that has sought to establish a connection between good teaching and improved learning (c.f. Trigwell and Prosser 1996; Prosser and Trigwell 1999) the further link to the work of those from ADUs has been harder to determine. In Australia, the Association for Directors of Academic Development or CADAD (2001) provided a benchmarking report which argued that the impact of ADU could be gauged in the following way: "The ADU has developed and maintains indications, metrics and standards that can be used to monitor, benchmark and report its performance and impact in respect to all aspects of its mission and core business. These metrics... are transparent, easily accessible and widely utilized by the staff of the unit to monitor individual and collective performance and impact" (p35). Such a definition, although appearing not to be aligned definitively to either extreme outlined above, does draw more towards clear and describable outcomes and importantly does not problematise 
the design of indicators and metrics and thus the measurement of academic development programs.

Gray and Radloff (2008) examine the concept of impact in academic development, referring to Dur and Glazer's (2005) definition of it as "the difference that a person's existence makes to increasing or reducing output" (p4). They suggest that the two extremes of impact evaluation described above can be characterized against two different interpretations that they term: rhetorical and conceptual. The rhetorical use often conflates other words such as achievement, influence, outcome, results, returns, success. They argue that this use of the term impact aims to persuade and to provide a positive view. Examples using such terms include Gibbs and Coffey (2004), Dearn (2005), Kahn and Macdonald (2004) and Bath and Smith (2004). The conceptual use is more interpretative and critical, analysing the place of impact in academic development and the examples that they cite include Kreber and Brook (2001), Kirkpatrick (1998) and Guskey (2000) who all examine impact as levels or layers from satisfaction (of participants and students), student learning through to institutional culture.

From a more pragmatic perspective, Bamber (2011) suggests that to evaluate the impact of an academic development program the first step is to consider the underlying theory of change (Connell \& Kubisch 1999) that is behind the program and from there examine the extent to which this change can be seen to have happened. This means identifying the links between the program and its expected outcomes and articulating first why and secondly how a change may happen. This, however, requires an acknowledgement that there will not be a simple connection between a change initiative and its outcomes (Trowler \& Bamber 2005). An approach used, for example by Bamber (2005) is RUFDATA (Reynolds and Saunders 1987) which examines reasons (or purposes), uses, foci, data (or evidence), audience, timing and agency.

Examining the impact of an academic development program designed around a complex set of interrelated processes and principles, and that espouses process and product outcomes, sets a methodological challenge. Sammons et al (2005) 
argue for mixed methods in situations where "complex and pluralistic social contexts demand analysis that is informed by multiple and diverse perspectives" (p221). Using a mixed methods approach, using both quantitative and qualitative methods, appears to offer an opportunity to find a way of ensuring that viewing impact from an extreme position can be reduced. Quantitative, mainly deductive methods can provide an opportunity to measure impact around "known" phenomena and central patterns of association, including inferences of causality, such as the amount of work undertaken and perceived effectiveness of the tutor (Ebert-May et al 2011; Rienties et al 2013; Stes et al 2010). Qualitative, mainly inductive methods can be introduced to allow for identification of previously unknown processes, explanations of why and how phenomena occurred, and the range of their effects, including those that may be hoped for or anticipated in the future (Pasick et al., 2009). A mixed methods approach requires more than simply collecting qualitative data from interviews, or collecting multiple forms of qualitative evidence or multiple types of quantitative responses. It involves the intentional collection of both quantitative and qualitative data and the combination of the strengths of each to answer specific research questions (Rienties \& Kinchin 2014). Combining data related to the more immediate causal impacts, described by the quantitative approach, with that suggested by the qualitative approach which are potentially incremental and not always apparent for some time, may however offer opportunities for academic developers to provide a view on both the initial and future impacts being achieved.

It could be argued that using a mixed methods approach to impact presents a challenge as each of these methods is driven by different epistemological assumptions - positivist and interpretivist (Greene, 2007). Whilst acknowledging that there can be tensions when these different philosophical approaches are combined, there is also an opportunity to transform these tensions into new knowledge. As such, we would argue that these are not necessarily competing positions. In combination they offer exploration at the micro level of individual perspectives in the context of a broader picture that covers as much of the participant cohort as possible. Taking this approach offers an opportunity to gain a view of both individual agency and a structural perspective. We argue that 
each method can inform the other so we can gain both breadth from a quantitative approach and 'thick' (Geertz, 1972) contextual depth from a qualitative. Using seemingly diverse approaches and giving primacy to the research problem allows the potential for valuing both 'objective' and 'subjective' data (Morgan, 2007). This can provide greater opportunity to validate ideas that emerge from different sets of data collected, or find contradictions that may expose assumptions made. In addition, there is the potential that such a mixed methods approach may bridge a gap between the 'immediate' responses gathered by a quantitative instrument and more forward looking reflexive responses gained by the qualitative approach. In this way a team can gain a view of the current impact, the perceived future impact and the reasons for both at that time. Such a mixed methods approach can enable impact to be acknowledged through different, yet related program interventions.

Change, in particular changed thinking and practice regarding teaching and learning, is the notion that seems to be most important when evaluating an academic development intervention. In the context of an academic development program, impact may be understood in terms of change of various types - a change in culture, thinking, beliefs, intentions or actions. These changes may appear at first almost imperceptible in terms of thought or belief within an individual which may in time become lived through actions, acculturated and in time part of the practices of the community - teaching group, department. Impact, then can be viewed as a long-term process that enables academics to interrogate their teaching, to explore the justifications for their practice and to question the underpinnings of what they do and how that shapes the ways in which students learn. However, viewing impact in this developmental, reflexive sense is difficult within the timeframe of an academic development program often a year to two years duration. The fact that individuals require time to go through a series of phases to make change is recognized in the literature (Kotter, 1995). Indeed, whilst small changes in practice based on 'teaching tips' are relatively easy to bring about, more fundamental thinking about teaching practice and long-term, reflective change is much more difficult to achieve and demonstrate within a short timeframe. There is also a danger that too much 
emphasis on change may, in itself be problematic as it implied that participants were deficient and need to change. The reality is that everyone changes the way they teach over time for various reasons. Some of the changes will be prompted by a critical incident and have a clear start point. Others may be more incremental and have no clear start or end. Some may be stimulated by an academic development program, a conversation in a corridor with a colleague, comments from students, reading a paper or just intuition. The reason may be clear or it may be obscure. An academic development program may provide a way of articulating and recognizing this, which may itself be an impact.

\section{Conclusions}

Although this paper is based on a study of a particular instance of evaluation impact of academic development and is contextual for this reason, the questions it raises about the nature of impact in academic development are relevant beyond this setting. We suggest possible ways through that go beyond this specific context and have relevance to the international community of academic developers.

By defining impact and articulating the ways it can be conceptualised we found that we were able to engage with the range of stakeholders effectively. The provision of a contextualised approach that recognised different roles and potential interpretations was given approval by the stakeholders who acknowledged the complexity and the value in understanding particular outputs as occurring through and over time. In addition we were able to relate the impact to the overall process of learning rather than relying upon simple shortterm outputs. This required dialogue with key stakeholders such as senior management and staff (course participant) representatives. Having spent time exploring the meaning of impact we found these discussions were of significant benefit, adding further to our understanding of the role of academic development.

Evaluating the impact of an academic development program in a way that captures both its aims and its real outcomes is undoubtedly challenging. The 
impact can be described in different ways to different audiences through a variety of methods. We argue that impact should be understood and described in multiple ways. What is important is that evaluations of impact start with a clear understanding of how impact is defined, what the aims of the program are, who the key stakeholders are, what the likely benefits are, how this will be achieved and what evaluation methods are most appropriate. We also argue for an approach to academic development that takes account of the range and variety of possible impacts.

We suggest that the impact of academic development is multiple and contextual and hence influenced by who is defining its aims and objectives and what change is being described. Impact can be understood from a personal perspective, in the way that each individual academic thinks about their teaching, their career, their place in the institution and their relationships with their colleagues and their students. It can be thought about from a teaching perspective more broadly, as a change in thinking about teaching or teaching practices. It can be thought about from a student perspective - as a change in learning or from a more superficial angle, as student satisfaction. It can be thought about from a management perspective - are staff in a school, department or unit changing in ways that meet needs perceived to be important (defined in various ways), it can be thought about from a strategic perspective - does the program further institutional objectives in some identifiable way. All these understandings of impact carry with them a set of values, both explicit and covert and as such, impact is an ideological proposition, reflecting the power relations in a particular context. Furthermore, while impact is often assumed to be positive, it can have negative or unforeseen consequences.

In our own evaluation of the impact of one academic development program we were forced to define what we meant by impact, to consider the assumptions underpinning this and how impact is conceptualized in this particular context. This caused us then to consider to whom the impact referred, what it meant and how it could best be evaluated. We had to consider what conceptual approach should be taken and what the implications were of adopting one over another? 
Drawing on the impact literature, we clarified our own definitions and explained these within our context and reported against that. We sought to produce an evaluation of impact that took account of both outcomes and process. We were clear to identify the range of stakeholders each with their own view on the nature of the impact. Through unpacking assumptions, stakeholders and context we sought a more transparent and contextually grounded approach. 


\section{References}

Atkinson, P. \& Delamont, S. (1985) Socialisation into Teaching: the research which lost its way British Journal of Sociology of Education 6 (3): 307-322

Bamber, V., Walsh, L., Juwah, C., \& Ross, D. (2006). New lecturer development programmes: A case study of Scottish higher education institutions. Teacher Development, 10(2), 207-231.

Bamber, V. (2011) Self-evaluative practice: Diversity and power, in M. Saunders, P. Trowler, V. Bamber, Reconceptualising Evaluation in Higher Education: The Practice Turn, Maidenhead: Open University Press

Barnett, R. (2000) University knowledge in an age of supercomplexity Higher Education 40 (4) 409-422

Bath, D., and Smith, C. (2004). Academic developers: An academic tribe claiming their territory in higher education. International Journal for Academic Development 9(1), 9-27.

Breakwell, G. (1986) Coping with threatened identities London: Routledge

Chalmers, D. and Gardiner, D. (2015) An evaluation framework for identifying the effectiveness and impact of academic teacher development programmes' Studies in Educational Evaluation, 46, 81-91

Council of Australian Directors of Academic Development (2011) Benchmarking Performance of Academic Development Units in Australian Universities, Australia, http://www.cadad.edu.au/pluginfile.php/401/course/section/78/Benchmarkin g_Report.pdf

Coles, C. (2013) Learning About Uncertainty in Professional Practice pp47-69 In L.S. Sommers \& J. Launer eds Clinical Uncertainty in Primary Care New York: Springer

Connell, J. and A. Kubisch (1998). Applying a Theory of Change Approach to the Evaluation of Comprehensive Community Initiatives: Progress, Prospects, and Problems. New Approaches to Evaluating Community Initiatives Volume 2: Theory, Measurement and Analysis. A. Kubisch, K. Fulbright Anderson and J. Connell. New York, The Aspen Institute: 15-44.

Dearn, J. (2005). The role and impact of faculty development on learning and teaching outcomes in higher education. Educational Developments, 6(1), 1-11.

Debowski, S. Emergent Shifts in Faculty Development (2011) In J Miller, To Improve The Academy, San Francisco: Jossey Bass

Department for Business, Innovation and Skills (2011) Higher Education: Students at the Heart of the System London: BIS 
Department of Education and Training (2014) Australian Awards for University Teaching, Wednesday 10 December Media Release

Dur, R., \& Glazer, A. (2005). The desire for impact. CESifo Working Paper No. 1535, Category 4:Labour Markets.

Diane Ebert-May, Terry L. Derting, Hodder, J., Momsen,J. L., Long, T. M. and Jardeleza, S. E (2011)., What We Say Is Not What We Do: Effective Evaluation of Faculty Professional Development Programs, BioScience

Vol. 61, No. 7 (July), pp. 550-558

Eraut, M. (2000) Non-formal learning and tacit knowledge in professional work British Journal of Educational Psychology 70: 113-136

Fanghanel, J. (2012) Being an Academic London: Routledge

Garbarino, S. and Holland, J. (2009). Quantitative and Qualitative Methods in Impact Evaluation and Measuring Results. GSDRC (Governance and Social Development Resource Centre.

Geertz, C. (1972). Thick descripton: Toward an interpretive theory of culture The interpretation of cultures: Selected essays (pp. 3-30). New York: Basic Books.

Gibbs, G. \& Coffey, M. (2004) The impact of training of university teachers on their teaching skills, their approach to teaching, and the approach to learning of their students. Active Learning in Higher Education, 5(1): 87-100.

Gosling, D. (2001) Educational development units in the UK - what are they doing five years on? International Journal for Academic Development 6 (1), 74-90

Gray, K. \& Radloff, R. (2008) The idea of impact and its implications for academic development work International Journal for Academic Development 13 (2) 97106

Greene, J. C. (2007). Mixed methods in social inquiry. San Francisco: John Wiley \& Sons.

Guskey, T. R. (2000) Evaluating professional development. Thousand Oaks, CA: Corwin

Henard, F. and Leprince-Ringuet, S. (2008) The Path to Quality Teaching in Higher Education, OECD-IMHE project, Quality of Teaching in Higher Education

Kahn, P., \& Macdonald, R. (2004, November). Reviews of the impact of staff and educational development: A means to improve the scholarly basis for our practice. Workshop presented at the 9th Annual SEDA Conference for Staff and Educational Developers, Birmingham, UK. 
Kirkpatrick, D. L. (1998). Evaluating training programs: The four levels (2nd ed.). San Francisco, CA: Berrett-Koehler

Kotter, J. (1995) Leading Change: Why Transformation Initiatives Fail Harvard Business Review 73 (2), 59-67

Kramer, M. (1974) Reality shock - Why nurses leave nursing. Mosby: St Louis

Kreber, C. (2011) 'Demonstrating Fitness for Purpose' in Evaluating the effectiveness of Academic Development: Principles and Practice L. Stefani (ed) Abingdon: Routledge

Kreber, C. and Brook, P. (2001) Impact evaluation of educational development programmes. International Journal for Academic Development, 6(2), 96-102.

Land, R. (2004), Educational Development: Discourse, identity and practice Maidenhead: OU Press

Loads, D. and Campbell, F. (2015) Fresh thinking about academic development: Authentic, transformative, disruptive? International Journal for Academic Development, online DOI: 10.1080/1360144X.2015.1083866

Lygo-Baker, S. (2006) Re-evaluating values: the impact of academic developers International Journal of Learning Vol 12

Manathunga, C. (2006). Doing Educational Development Ambivalently: Applying post-colonial metaphors to educational development? International Journal for Academic Development, 11(1), 19-29.

Morgan, D. L. (2007). Paradigms lost and pragmatism regained: Methodological implications of combining qualitative and quantitative methods. Journal of Mixed Methods Research, 1(1), 48-76.

Morley, L. (2003) Quality and power in higher education. Philadelphia, PA: Society for Research into Higher Education \& Open University Press.

Palmer, P. (1998) The Courage to Teach San Francisco: Jossey Bass

Pasick, R. J., Burke, N. J., Barker, J. C., Galen, J., Bird, J. A., Otero-Sabogal, R., et al. (2009). Behavioral theory in a diverse society: Like a compass on Mars. Health Education Behavior, 36(5), 11S-35S.

Peseta, T. A. (2014) Agency and stewardship in academic development: the problem of speaking truth to power, International Journal for Academic Development, 19 (1), 65-69,

Prosser, M., \& Trigwell, K. (1999). Understanding learning and teaching: The experience in higher education. Buckingham: SRHE \& Open University Press. 
Reynolds, J. \& Saunders, M. (1987) Teacher responses to curriculum policy: Beyond the 'delivery' metaphor, in J. Calderhead (ed.) Exploring Teachers' Thinking, London: Cassell

Rienties, B., \& Kinchin, I. (2014). Understanding (in)formal learning in an academic development programme: A social network perspective. Teaching and Teacher Education. (39), 123-135.

Rienties, B., Brouwer, N., Lygo-Baker, S. (2013). The effects of online professional development on teachers' beliefs and intentions towards learning facilitation and technology, Teaching and Teacher Education. 29:122-131.

Rivers, J. (2005) Academic Staff Development: A summary of a synthesis of research on the impact of academic staff development programmes on student outcomes in undergraduate tertiary study, Summary Report to the Ministry of Education Te Tāhuhu o te Mātauranga, New Zealand

Rogers, P. (2008) Using Programme Theory to Evaluate Complicated and Complex Aspects of Interventions. Evaluation 14(1), 29-48

Rowland, S. (2003). Academic development: a practical or theoretical business? In H. Eggins and R. MacDonalds (eds) The Scholarship of Academic Development. Buckingham: SRHE and Open University Press

Sammons, P., Siraj-Blatchford, I., Sylva, K., Melhuish, E., Taggard, B., \& Elliot, K. (2005). Investigating the effects of pre-school provision: Using mixed methods in the EPPE research. International Journal of Social Research Methods, 8(3), 207224.

Smith, H. J. (2004). The impact of staff development programmes and activities. In D. Baume \& P. Kahn(Eds.), Enhancing staff \& educational development (pp. 96117). Oxford, UK: Routledge Falmer.

Smutylo, T. (2001). Crouching Impact, Hidden Attribution: Overcoming Threats in Learning Development Programs. (at: http://www.idrc.ca/uploads/userS/10899909431CROUCHING IMPACT.pdf, last accessed 06052011).

Southwell, D. and Morgan, W. (2010) Leadership and the impact of academic staff development and leadership development on students learning outcomes in higher education: A review of the literature, A Report of the Australian Learning and Teaching Council (ALTC), Canberra: ALTC

Stefani, L. (2011) Evaluating the Effectiveness of Academic Development: Principles and Practice Abingdon: Routledge

Stes, A., Min-Leliveld, M., Gijbels, D., \& Van Petegem, P. (2010). The impact of instructional development in higher education: The state-of-the-art of the research. Educational Research Review, 5(1), 25-49. 
Stes, A., Coertjens, L., \& Van Petegem, P. (2010). Instructional development for teachers in higher education: impact on teaching approach. Higher education, 60(2), 187-204.

Sutherland, K. A. (2013) The importance of critical reflection in and on academic development, International Journal for Academic Development, 18 (2), 111-113

Trigwell, K. \& Prosser, M. (1996) Changing approaches to teaching: a relational perspective, Studies in Higher Education, 21, 275-284.

Trowler, P. \& Bamber, V. (2005) Compulsory Higher Education Teacher Training: Joined-up policies, institutional architectures and enhancement cultures International Journal for Academic Development 10 (2): 79-93

Turner, N., Oliver, M. Mckenna, C., Hughes, J. Smith, H. Deepwell, F. Shreves. L. (2013) Measuring the impact of the UK Professional Standards Framework for Teaching and Supporting Learning (UKPSF) Staff and Educational Development Association, Higher Education Academic Project.

Webb, G. (1996). Understanding Staff Development. Buckingham: The Society for Research into Higher Education and Open University Press.

White, H. (2010) A Contribution to Current Debates in Impact Evaluation Evaluation 16 (4): 153-164 